\title{
DIAGNOSTIC EVALUATION OF POWER FADE PHENOMENA AND CALENDAR LIFE REDUCTION IN HIGH-POWER LITHIUM-ION BATTERIES
}

\author{
Robert Kostecki and Frank McLarnon \\ Environmental Energy Technologies Division \\ Lawrence Berkeley National Laboratory \\ University of California, Berkeley, CA 94720, USA
}

\begin{abstract}
High-power Li-ion cells with graphite anodes and $\mathrm{LiNi}_{0.8} \mathrm{Co}_{0.15} \mathrm{Al}_{0.05} \mathrm{O}_{2}$ cathodes that were cycled and stored at elevated temperatures showed a significant impedance rise and capacity fade, which were associated primarily with the $\mathrm{LiNi}_{0.8} \mathrm{Co}_{0.15} \mathrm{Al}_{0.05} \mathrm{O}_{2}$ cathode. A combination of electrochemical, physical, and chemical diagnostic techniques, including Raman, SEM, and current-sensing AFM, was used to characterize the cathodes from these cells in order to produce a clear picture of the mechanism for cell degradation. Systematic Raman mapping of 50 x $80 \mu \mathrm{m}$ areas at $0.9 \mu \mathrm{m}$ spatial resolution produced semi-quantitative composition maps of cathode surfaces. Raman microscopy surface composition maps and SEM images of cathodes from tested cells revealed that cell cycling or storage at elevated temperatures led to significant changes in the $\mathrm{LiNi}_{0.8} \mathrm{Co}_{0.15} \mathrm{Al}_{0.05} \mathrm{O}_{2}$ /elemental-carbon surface concentration ratio. The loss of conductive carbon correlated with the power and capacity fade of the tested cathodes and the loss of surface electronic conductivity.
\end{abstract}

Key words: Li-ion battery, cathode, carbon retreat, conductivity, Raman, AFM

\section{Introduction}

Lithium-ion batteries are being seriously considered for application in all-electric vehicles (EV) and hybrid electric vehicles (HEV's) because of their high power and energy densities [1,2]. The U.S. Department of Energy's Advanced Technology Development (ATD) Program supports the development of high-power $\mathrm{LiNi}_{0.8} \mathrm{Co}_{0.15} \mathrm{Al}_{0.05} \mathrm{O}_{2} / \mathrm{EC}-\mathrm{EMC}, \quad 1.2 \mathrm{M}$ $\mathrm{LiPF}_{6} /$ graphite batteries for hybrid electric vehicle applications [3]. A major 
goal of the ATD Program is to develop a detailed understanding of the power and capacity fade mechanisms of a single cell chemistry designed for the HEV application and to develop predictive models for the accelerated life test behavior based on these mechanisms. For this purpose, this cell chemistry has been subjected to elevated-temperature calendar life and lifecycle testing with an pulse-type profile over a very limited range of state-of-charge (SOC) [4].

Diagnostic evaluations of Li-ion cells that were aged and/or cycled under various conditions were carried out to determine the mechanisms responsible for the cell power loss that accompanies life tests at elevated temperatures. Many cells have been examined to determine the mechanisms for capacity and power fade, using a wide range of diagnostic techniques that were developed and refined during studies of the ATD cells [5]. Impedance measurements of the cell components indicated that the $\mathrm{LiNi}_{0.8} \mathrm{Co}_{0.15} \mathrm{Al}_{0.05} \mathrm{O}_{2}$ cathode is primarily responsible for the observed cell power loss at elevated temperatures, similarly to the $\mathrm{LiNi}_{0.8} \mathrm{Co}_{0.2} \mathrm{O}_{2}$ cathode, which was studied in our previous work [6]. Possible causes of the increase in cathode impedance include formation of an electronic and/or ionic barrier at the cathode surface. However, the observation that, in these cells, power fade is always accompanied by a loss of cell discharge capacity suggests that the mechanism of degradation is more complicated and may consist of multiple processes, which may be a somewhat general phenomenon that affects several types of cathodes.

X-ray diffraction spectroscopy failed to detect noticeable changes in the bulk structure of the tested cathodes, and no evidence of material structural degradation or formation of new phases was found. In this study we focused our attention on cathode surface processes, which we believe have a dominant effect on impedance behavior. A systematic diagnostic evaluation of $\mathrm{LiNi}_{0.8} \mathrm{Co}_{0.15} \mathrm{Al}_{0.05} \mathrm{O}_{2}$ cathodes removed from high-power Li-ion cells, which were stored and/or cycled at elevated temperatures, was carried out. The application of local probe techniques such as current-sensing AFM and Raman microscopy to characterize physico-chemical properties of the electrode surface at nanometer resolution can provide unique insight into the complex mechanism of the detrimental processes that are likely responsible for the composite cathode capacity fade and impedance increase.

\section{Experimental}

High-power $\mathrm{Li}$-ion cells with a $\mathrm{LiNi}_{0.8} \mathrm{Co}_{0.15} \mathrm{Al}_{0.05} \mathrm{O}_{2}$ cathode, a synthetic graphite anode, 1.2 $\mathrm{M} \mathrm{LiPF}_{6}+$ ethylene carbonate + ethyl-methyl carbonate (EC/EMC) electrolyte, and a Celgard ${ }^{\circledR} 2300$ separator, were manufactured, aged, cycled, and/or abused and then characterized under the ATD Program $[3,4]$. We compared a fresh cathode with cathodes taken from 
cells that were aged or cycled at elevated temperatures for up to 68 weeks, losing up to $52 \%$ of their initial power and $24 \%$ of their initial capacity.

The samples were collected from the cathodes $\sim 2.5 \mathrm{~cm}$ away from the current collector tab, washed in pure dimethyl carbonate (DMC), and soaked DMC for 30 minutes after removal from Li-ion cells inside an argonfilled glove box. This procedure removed electrolyte salt from the electrode to prevent its reaction with air and moisture. An integrated Raman microscope system "Labram" made by ISA Groupe Horiba was used to analyze and map the cathode surface structure and composition. The excitation source was an internal He-Ne $(632 \mathrm{~nm}) 10 \mathrm{~mW}$ laser. The power of the laser beam was adjusted to $0.1 \mathrm{~mW}$ with neutral filters of various optical densities. The size of the laser beam at the sample was $\sim 1.2 \mu \mathrm{m}$.

We used current-sensing atomic force microscopy (CSAFM) to measure and image-map the electronic conductivity of individual grains of the $\mathrm{LiNi}_{0.8} \mathrm{Co}_{0.15} \mathrm{Al}_{0.05} \mathrm{O}_{2}$ powder (Fuji Chemical) that was used to fabricate ATD Program composite cathodes. The powder was pressed into a gold foil to produce randomly scattered particles of $\mathrm{LiNi}_{0.8} \mathrm{Co}_{0.15} \mathrm{Al}_{0.05} \mathrm{O}_{2}$ in good electronic contact with the Au substrate. The microscope consisted of a Molecular Imaging (MI) scanning probe microscope coupled with a Park Scientific Instruments (PSI) AutoProbe Electronic Module. The Si atomic force microscope (AFM) tips were coated with a thin conductive layer of $\mathrm{W}_{2} \mathrm{C}$. All CSAFM experiments were performed in constant-force mode with controlled oxide-tip voltage difference. A single scan of the tip over the sample surface simultaneously produced two images: a topographic image and a conductance image; the latter represents $\mathrm{Au} / \mathrm{LiNi}_{0.8} \mathrm{Co}_{0.15} \mathrm{Al}_{0.05} \mathrm{O}_{2}$ - tip current variations during scanning at a given sample-tip voltage difference. CSAFM imaging was conducted in a small glove box specially designed for scanning-probe microscopy tests under a controlled $\mathrm{N}_{2}$ atmosphere.

Scanning electron microscope (SEM) images were recorded using a Jeol field emission microscope, model JSM 634OF. Sample preparation was carried out in the inert-atmosphere glove-box. The samples were then sealed in a small bottle for transportation to the AC sputtering chamber where they were coated with gold-palladium prior of being transferred to the SEM vacuum chamber.

\section{Results and Discussion}

Cathode surface-average Raman spectra were produced with the Raman microscope. Raman spectra were collected from multiple $52 \times 75 \mu \mathrm{m}$ sections of the cathode surfaces at $0.7 \mu \mathrm{m}$ resolution and averaged into one representative spectrum for each cathode. MicroRaman surface-average 
spectra of the cathode from the virgin cell, and cathodes removed from cells which lost 10, 24, 34 and $52 \%$ of power are shown in Figure 1. The Raman spectra of all cathodes are dominated by two groups of bands: a broad maximum centered at $\sim 510 \mathrm{~cm}^{-1}$, characteristic for $\mathrm{LiNi}_{0.8} \mathrm{Co}_{0.15} \mathrm{Al}_{0.05} \mathrm{O}_{2}$ oxide, and two peaks at $\sim 1350$ and $\sim 1600 \mathrm{~cm}^{-1}$, which correspond to the $\mathrm{D}$ and $\mathrm{G}$ bands of elemental carbon, respectively. Raman spectroscopy is a particularly useful tool for characterizing the nearsurface structure of carbons because of its relatively large Raman scattering cross-section. Recorded average spectra of the composite cathodes display strong carbon bands, which are predominant at almost all locations and originate from graphite and carbon

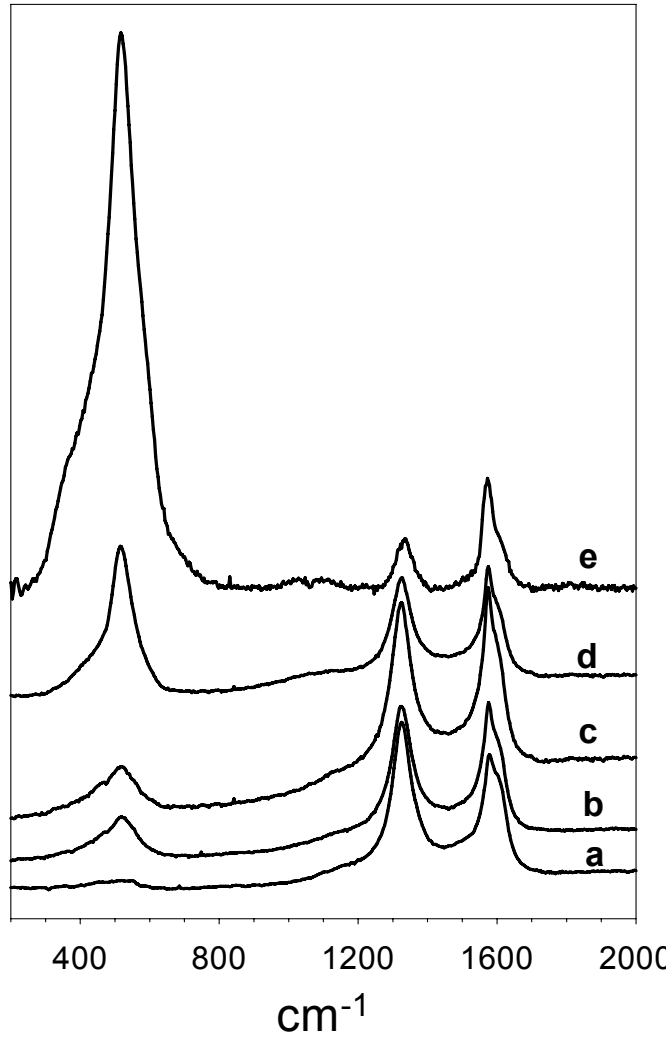

Figure 1. Average Raman microscope spectra of the fresh composite $\mathrm{LiNi}_{0.8} \mathrm{Co}_{0.15} \mathrm{Al}_{0.05} \mathrm{O}_{2}$ cathode (a), and the cathode from cells that exhibited 10 (b), 24 (c), 34 (d), and 52\% (e) power loss.

black conductive additives.

The intensity ratio between the three major bands at $\sim 510 \mathrm{~cm}^{-1}$ $\left(\mathrm{LiNi}_{0.8} \mathrm{Co}_{0.15} \mathrm{Al}_{0.05} \mathrm{O}_{2}\right)$, and $1350,1580 \mathrm{~cm}^{-1}$ (carbon) represent a semiquantitative comparison because of the different Raman scattering crosssections of $\mathrm{LiNi}_{0.8} \mathrm{Co}_{0.15} \mathrm{Al}_{0.05} \mathrm{O}_{2}$ and carbon. However, it is clear from Fig. 1 that the active material/elemental-carbon surface concentration ratio increases with the increasing extent of cell and cathode degradation and is substantially higher for the cells that lost 10,24,34\% of power compared with the fresh cell. The most drastic change in the oxide/carbon surface concentration ratio was observed in the cathode from the cell that lost $52 \%$ of its original power. Interestingly, the cathode surface state of charge varied between and within large individual agglomerates of active material and, at some locations, the spectra correspond to fully charged material, even though the cell was fully discharged at the end of testing and before disassembly. 

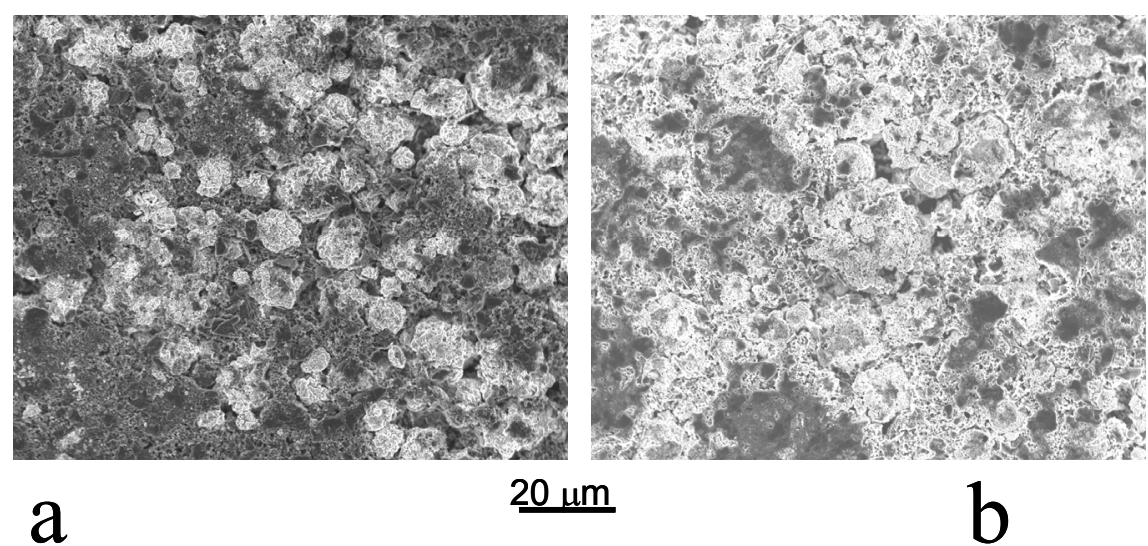

a

$20 \mathrm{um}$

Figure 2. SEM images of the fresh composite $\mathrm{LiNi}_{0.8} \mathrm{Co}_{0.15} \mathrm{Al}_{0.05} \mathrm{O}_{2}$ cathode (a), and the cathode removed from a cell that lost $52 \%$ of its original power.

Figure 2 shows $\mathrm{SEM}$ images of a composite $\mathrm{LiNi}_{0.8} \mathrm{Co}_{0.15} \mathrm{Al}_{0.05} \mathrm{O}_{2}$ cathode extracted from a fresh cell and a cell that was cycled at $45^{\circ} \mathrm{C}$ for 68 weeks and lost $52 \%$ of its original power. Note that the surface of the fresh cathode consists of 5-20 $\mu \mathrm{m}$ agglomerates of $\mathrm{LiNi}_{0.8} \mathrm{Co}_{0.15} \mathrm{Al}_{0.05} \mathrm{O}_{2}$ (bright particles) and a dark fine particle coating, most likely carbon black, which is non-uniformly distributed across the surface. Interestingly, the surface morphology of the cathode from the tested cell reveals a noticeable change. There remain a few areas that show no or little change compared to the original morphology, whereas in most regions the black carbon coating has almost entirely disappeared from the surface leaving the active material fully exposed. This observation is in full agreement with our Raman spectra, which showed a dramatic decrease of the carbon signal in the tested cathodes.

In order to better understand the potential role of carbon retreat/redistribution on the cathode impedance rise we measured the surface electronic conductivity of these cathodes with CSAFM. Figure 3 shows CSAFM images of surface conductance (right-hand panel) and topography (left-hand panel) of a representative $5 \times 5 \mu \mathrm{m}$ region of the composite $\mathrm{LiNi}_{0.8} \mathrm{Co}_{0.15} \mathrm{Al}_{0.05} \mathrm{O}_{2}$ cathode surface at $1.0 \mathrm{~V}$ tip-sample voltage difference for (A) a fresh cell; and (B) a cathode from the cell that lost $34 \%$ of its power. The surface morphology images of both cathodes (left-hand panel) show large polycrystalline agglomerates and reveal no significant changes in the cathode surface topography in tested cells. This result is contrary to our earlier study of $\mathrm{LiNi}_{0.8} \mathrm{Co}_{0.2} \mathrm{O}_{2}$ cathodes, which showed that considerable amounts of nanocrystalline deposits accumulated in the cathode inter-granular spaces and across the crystal planes [6,7].

In the conductance image, a dark color represents high electronic conductance, whereas a white color corresponds to areas of low or zero electronic conductance. Taking into account that the tip is in physical contact 
with the oxide, the magnitude of the current is determined by the local electronic properties of the electrode and the tip, and the tip-sample voltage difference. The surface conductance image of the cathode from the fresh cell exhibits areas of mostly excellent electronic conductance and only few insulating regions. Highly conductive graphite and acetylene black certainly contribute to the observed high tip current. The $\mathrm{LiNi}_{0.8} \mathrm{Co}_{0.15} \mathrm{Al}_{0.05} \mathrm{O}_{2}$ may also contribute to the tip current, but its contribution is substantially lower than that of carbon. The insulating areas on the cathode surface are most likely associated with the presence of PVDF binder, a solid electrolyte interphase (SEI), and/or unusual surface morphology (e.g., deep crevices).

The conductance image of the tested cathode reveals that almost the entire electrode surface became insulating except for a few locations, mainly in the deep crevices and intergranular spaces, which remained conductive.

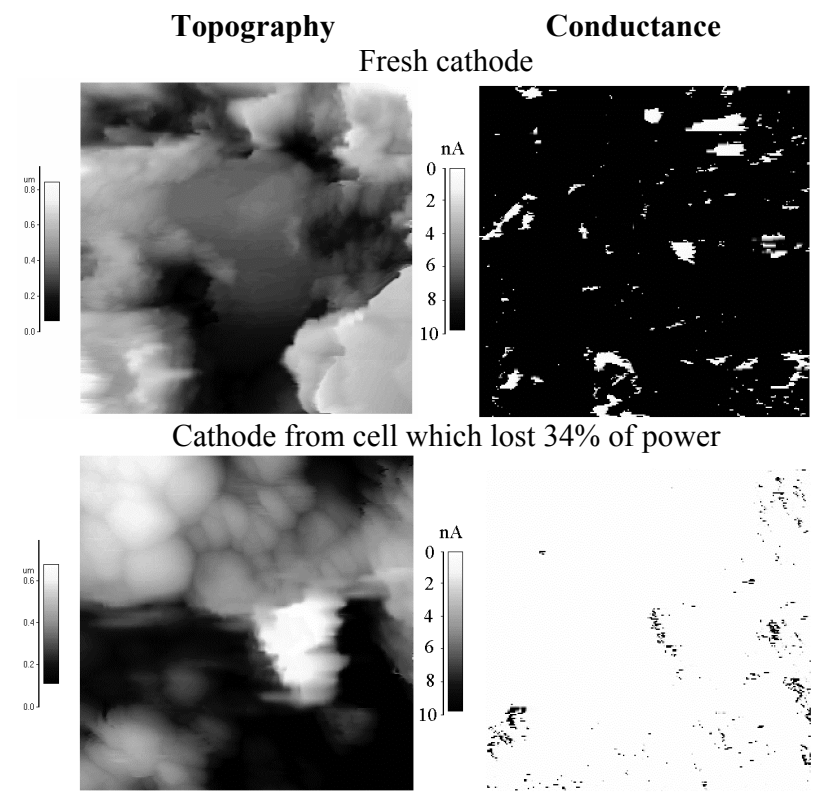

Figure 3. CSAFM images of surface conductance (right-hand panel, black areas are conductive) and topography (left-hand panel) of a $5 \times 5 \mu \mathrm{m}$ region of the cathode surface at $1.0 \mathrm{~V}$ tip-sample voltage difference.

Previous results for $\mathrm{LiNi}_{0.8} \mathrm{Co}_{0.2} \mathrm{O}_{2}$ cathodes [6,7] also showed a complete lack of conductivity of the cathode surface, consistent with loss of electronic contact between particles at the electrode surface and the remainder of the electrode. Another plausible explanation for the observed phenomena could be formation of a very thin SEI layer. A relatively thick layer of $\mathrm{Li}_{2} \mathrm{CO}_{3}$ and $\mathrm{P}-, \mathrm{O}-$ and $\mathrm{F}$ - containing compounds forms upon storage of $\mathrm{LiNi}_{1-\mathrm{y}} \mathrm{Co}_{\mathrm{y}} \mathrm{O}_{2}$ in $\mathrm{LiPF}_{6}$-containing electrolyte at $80-90^{\circ} \mathrm{C}$, as found in $[8,9]$. However, our 
Raman and infrared measurements revealed no observable SEI layer on the cathode surface. On the other hand, the presence of charged material at the cathode surface may also indicate that some particles of $\mathrm{LiNi}_{0.8} \mathrm{Co}_{0.15} \mathrm{Al}_{0.05} \mathrm{O}_{2}$ became electrically disconnected from the remaining part of the cathode due to mechanical stress and/or carbon additive retreat.

A reduction in conductance of portions of the cathode can easily explain the observed increase in cell impedance as well as loss of cathode capacity via isolation of oxide active material. Particle isolation is also in concert with our observations of carbon retreat or rearrangement in tested cathodes. These results represent the most clear and obvious difference (compared to other diagnostic studies) in cathode characteristics after prolonged cell tests at elevated temperatures.

\section{Acknowlegement}

This work was supported by the Assistant Secretary for Energy Efficiency and Renewable Energy, Office of FreedomCAR and Vehicle Technologies of the U.S. Department of Energy under Contract No. DEAC03-76SF00098. The authors gratefully acknowledge the tested cells, help, and advice provided by the ATD Program participants.

\section{REFERENCES}

1. G. Nagasubramanian, R.G. Jungst, D.H. Doughty, J. Power Sources, 83, (1999) 193

2. Q. Wu, W. Lu, J. Prakash, J. Power Sources, 88 (2000) 237.

3. "FY 2000 Progress Report for the Advanced Technology Development Program," U.S. Department of Energy, Office of Advanced Automotive Technologies, Washington, D.C. (December 2000).

4. "FY 2001 Progress Report for the Advanced Technology Development Program," U.S. DOE OAAT, February 2001

5. "Handbook of Diagnostic Techniques", Lawrence Berkeley National Laboratory Report no. LBID-2464, April 2003.

6. A. X. Zhang, P. N. Ross, Jr., R. Kostecki, F. Kong, S. Sloop, J. B. Kerr, K. Striebel, E. Cairns, and F. McLarnon, J. Electrochem. Soc. 148, A463 (2001).

7. R. Kostecki and F. McLarnon, Electrochem. Solid State Lett., 5, A164 (2002).

8. A. M. Andersson, D. P. Abraham, R. Haasch, S. MacLaren, J. Liu, and K. Amine, J. Electrochem. Soc., 149, A1358 (2002).

9. D. Ostrowskii, F. Ronci, B. Scrosati, and P. Jacobsson, J. Power Sources, 94, 183 (2001). 